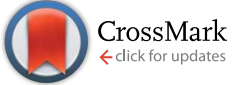

Cite this: Chem. Sci., 2016, 7, 1057

\title{
Chiral Brønsted acid-catalyzed enantioselective Friedel-Crafts reaction of 2-methoxyfuran with aliphatic ketimines generated in situ $\dagger$
}

\author{
Azusa Kondoh, ${ }^{a}$ Yusuke Ota, ${ }^{\text {b }}$ Takazumi Komuro, ${ }^{\text {F }}$ Fuyuki Egawa, ${ }^{\mathrm{b}}$ Kyohei Kanomata ${ }^{\mathrm{b}}$ \\ and Masahiro Terada*ab
}

An enantioselective Friedel-Crafts reaction with aliphatic ketimines generated in situ from hemiaminal ethers catalyzed by a chiral Brønsted acid was investigated. The reaction of 2-methoxyfuran with (thio) hydantoin-derived hemiaminal methyl ether proceeded under the influence of a chiral phosphoric acid catalyst to afford the corresponding adduct possessing a quaternary stereogenic center in high yield with high enantioselectivity. Theoretical studies were also conducted to clarify the mechanism of the stereochemical outcome and the major factors contributing to the efficient enantioselection.

Received 26th August 2015

Accepted 29th October 2015

DOI: $10.1039 / \mathrm{c} 5 \mathrm{sc} 03175 \mathrm{c}$

www.rsc.org/chemicalscience

enantioselective reduction of ketimines. ${ }^{6}$ To establish the enantioselective Friedel-Crafts reaction of aliphatic ketimines followed by the acquisition of mechanistic insight into the stereo-determining step, we designed the reaction system shown in Scheme 1.

For the development of the reaction employing aliphatic ketimines as a substrate, one often encounters a problem based not only on poor reactivity of aliphatic ketimines but also on their stability and synthetic difficulty. Thus we envisioned utilizing thiohydantoin derivatives $\mathbf{4}$ and hydantoin derivatives 5, which possess a hemiaminal ether moiety, as precursors for the aliphatic ketimines. With these substrates, the corresponding ketimines are generated in situ through the ment of reactions applicable to a range of ketimines substituted by alkyl groups is still a challenging topic. ${ }^{3}$ In addition, indoles and pyrroles are the only nucleophiles that have achieved a high enantioselectivity so far. In this context, we envisaged to develop a new enantioselective Friedel-Crafts reaction of aliphatic ketimines that have a variety of alkyl substituents with the expanding scope of nucleophiles using chiral phosphoric acid (CPA) as a chiral Brønsted acid catalyst. ${ }^{4}$ From a mechanistic viewpoint of the chiral phosphoric acid-catalyzed reaction, the origin of the stereochemical outcome in the carbon-carbon $(\mathrm{C}-$ C) bond-forming reaction of the aliphatic ketimine has scarcely been investigated ${ }^{5}$ despite conducting detailed studies of the

${ }^{a}$ Research and Analytical Center for Giant Molecules, Graduate School of Science, Tohoku University, Aoba-ku, Sendai 980-8578, Japan. E-mail: mterada@m.tohoku. ac.jp

${ }^{b}$ Department of Chemistry, Graduate School of Science, Tohoku University, Aoba-ku, Sendai 980-8578, Japan

$\dagger$ Electronic supplementary information (ESI) available: Experimental procedures, exploratory investigation of the reaction conditions, characterization data and DFT studies. CCDC 1405286. For ESI and crystallographic data in CIF or other electronic format see DOI: $10.1039 / \mathrm{c} 5 \mathrm{sc} 03175 \mathrm{c}$

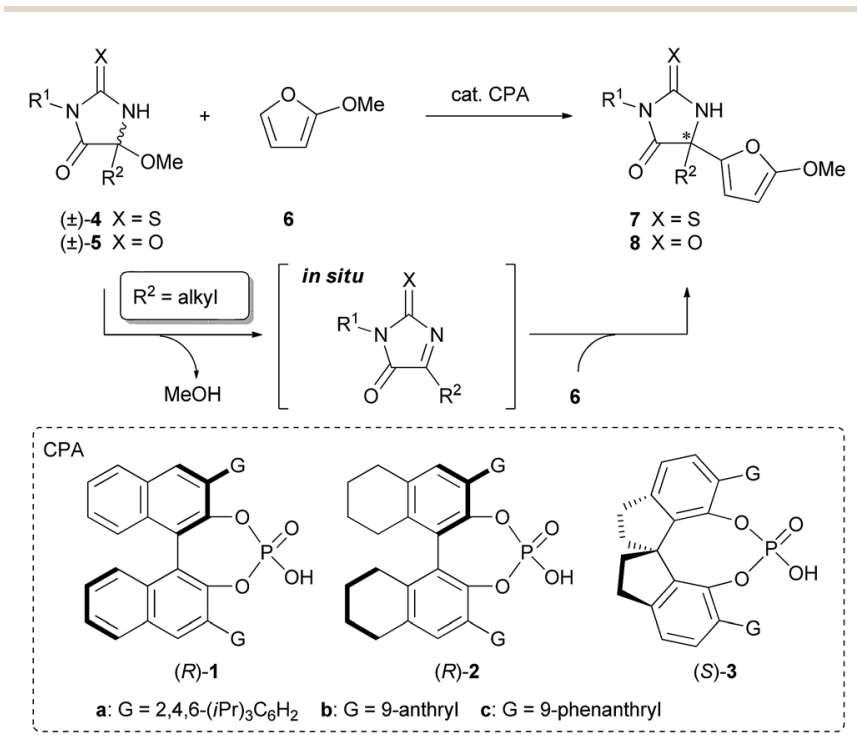

Scheme 1 Reaction design. 
elimination of alcohols under the influence of a Brønsted acid catalyst, ${ }^{7}$ and an imine carbon is activated by an electronwithdrawing group and there is a sterically less congested environment around the imine carbon because of their planarity. The utilization of (thio)hydantoin derivatives as substrates is also attractive from the synthetic point of view. The products of the designed reaction are (thio)hydantoin derivatives that have a quaternary stereogenic center at the 5-position, these are known as an important class of biologically active molecules with broad medicinal and agrochemical applications, ${ }^{8-11}$ and can act as precursors of $\alpha$-amino acid derivatives by hydrolysis. Furthermore, 2-methoxyfuran (6) was chosen as a reactant to expand the scope of nucleophiles, of which the product subunit can potentially function as a handle for further manipulation of the products. ${ }^{\mathbf{1 2}}$ Herein we report the enantioselective Friedel-Crafts reaction of 2-methoxyfuran with aliphatic ketimines generated in situ catalyzed by chiral phosphoric acid to provide (thio)hydantoin derivatives containing a quaternary stereogenic center in a highly stereoselective manner. Theoretical studies were also conducted to clarify the mechanism of the stereochemical outcome and the major factors contributing to the efficient enantioselection.

The initial experiment was performed with racemic hemiaminal methyl ether $\mathbf{4 a}$, having a methyl group as a substituent on the imine carbon, and 2-methoxyfuran (6) in the presence of a catalytic amount of chiral BINOL-derived phosphoric acid $(R)$ 1a in toluene (Table 1, entry 1). Pleasingly, the reaction proceeded smoothly in the presence of molecular sieves (MS) 5A which were employed to scavenge methanol generated during the formation of the ketimine. The desired product 7a was obtained at a high yield albeit with moderate enantioselectivity. Evaluation of several phosphoric acids including chiral BINOLderived $(R)-\mathbf{1}$ having different substituents at the 3 and $3^{\prime}$ -

Table 1 Screening of reaction conditions ${ }^{a}$

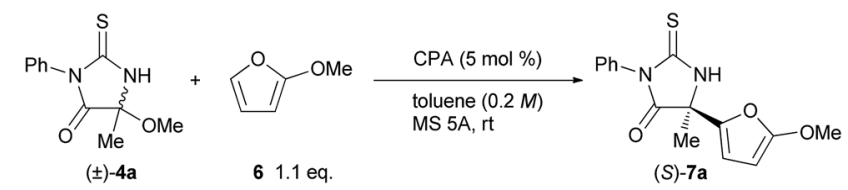

\begin{tabular}{lllll}
\hline Entry & CPA & Time $(\mathrm{h})$ & Yield $^{b}(\%)$ & ee $^{c}(\%)$ \\
\hline 1 & $(R)-\mathbf{1 a}$ & 4 & 92 & 57 \\
2 & $(R)-\mathbf{- 1} \mathbf{b}$ & 6 & 84 & 84 \\
3 & $(R)-\mathbf{- 1}$ & 4 & 68 & 75 \\
4 & $(R)-\mathbf{b}$ & 4 & 76 & 76 \\
5 & $(R)-\mathbf{2 c}$ & 6 & 68 & 70 \\
6 & $(S)-\mathbf{3 b}$ & 4 & 86 & 68 \\
7 & $(S)-\mathbf{3 c}$ & 4 & 94 & 92 \\
$8^{d}$ & $(S)-\mathbf{3 c}$ & 4 & $>99$ & 93
\end{tabular}

${ }^{a}$ Reaction conditions: $4 \mathrm{a}(0.10 \mathrm{mmol}), 6(0.11 \mathrm{mmol}), \mathrm{CPA}(5.0 \mu \mathrm{mol})$, MS 5A $(100 \mathrm{mg})$, toluene $(0.50 \mathrm{~mL}) .{ }^{b}$ Isolated yields. ${ }^{c}$ Enantiomeric excess of $7 \mathbf{a}$ was determined by chiral stationary phase HPLC analysis. Absolute configuration of $7 \mathbf{a}$ was determined to be $S$ by X-ray crystallographic analysis. ${ }^{14}$ See the ESI for detail. ${ }^{d}$ Benzene was used as a solvent instead of toluene. positions, chiral $\mathrm{H}_{8}$-BINOL-derived $(R)-2$, and chiral SPINOLderived $(S)$-3, revealed that $(S)$-3c was the optimal phosphoric acid and resulted in a $94 \%$ yield with $92 \%$ ee (entry 7 ). Further improvement in both yield and ee value was achieved by using benzene as the solvent instead of toluene (entry 8$).{ }^{13}$

In order to clarify the origin of the stereochemical outcome, we then conducted theoretical studies of the transition states of the stereo-determining $\mathrm{C}-\mathrm{C}$ bond-forming step. Four transition structures of the $\mathrm{C}-\mathrm{C}$ bond-forming step were possible through the combination of the re- and $s i$-faces of the pro-chiral reactants, the ketimine and 2-methoxyfuran (6) (Fig. 1). In the transition states TSss affording $(S)$-7a, the $s i$-face of the ketimine reacts with the re- and $s i$-faces of 2-methoxyfuran (6), generating TSs-re and TSs-si, respectively. Similarly, TSr-si and TSr-re were generated for TSrs, which results in the formation of $(R)-7 \mathbf{a}$. The geometries of the TSss and TSrs were fully optimized and characterized using frequency calculations at the B3LYP level of density functional theory with the $6-31 G^{*}$ basis set. ${ }^{15,16}$ After thorough screening of plausible transition structures to determine the relative location of the reactants and the chiral phosphoric acid catalyst, four transition structures of the corresponding configurations were localized. In each optimized structure, the ketimine and 2-methoxyfuran (6) interact with the catalyst through an $\mathrm{O} \cdots \mathrm{H} \cdots \mathrm{N}$ hydrogen bond and a $\mathrm{C}-\mathrm{H} \cdots \mathrm{O}$ hydrogen bond, respectively. ${ }^{17}$ The TSs-si and TSr-re were energetically less favorable than the TSs-re and TSr-si, presumably due to the steric repulsion between the $N$-phenyl substituent of the ketimine and the methoxy group of $\mathbf{6}$ (dashed curves in Fig. 1). More importantly, the transition state TSs-re [which affords $(S)$-7a] was more stable than the TSr-si [which

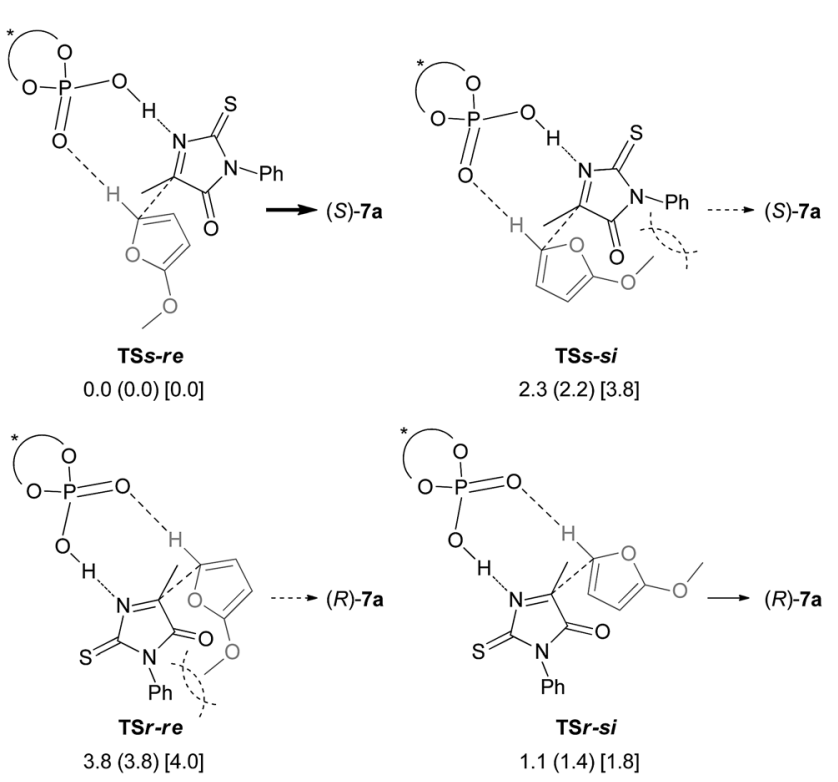

Fig. 1 Schematic representation models of TSss and TSrs. The relative energies of the optimized structures in the gas phase are shown in kcal $\mathrm{mol}^{-1}$, with relative Gibbs free energies $\left(\mathrm{kcal} \mathrm{mol}^{-1}\right)$ in parentheses. The relative energies $\left(\mathrm{kcal} \mathrm{mol}^{-1}\right)$ which were obtained by single-point energy calculations at the B3LYP/6-311+G** level using the SCRF method based on PCM ( $\epsilon=2.2706$ for benzene) are shown in brackets. ${ }^{18}$ Steric repulsions are indicated by dashed curves. 
affords $(R)-7 \mathbf{a}]$. The $(S)$-selective pathway was energetically favorable for the reaction catalyzed by $(S)-3 \mathbf{c}$, which is consistent with the experimental results.

Further structural analyses of TSs-re and TSr-si allowed the identification of the major factors contributing to the efficient enantioselection. Three-dimensional transition structures of TSs-re and TSr-si are illustrated in Fig. 2. As pointed out in Fig. 1, the hydrogen atom at the 5-position of 2-methoxyfuran (6) interacts with chiral phosphoric acid $(S)-3 \mathrm{c}$ through the $\mathrm{C}-\mathrm{H} \cdots \mathrm{O}$ hydrogen bond (dashed blue lines in Fig. 2). In fact, the distances between the hydrogen and oxygen atoms $(1.99 \AA$ in TSs-re and 2.05 $\AA$ in TSr-si) are significantly shorter than the sum of the van der Waals radii of the hydrogen and oxygen atoms ( ca. $2.7 \AA$ ). Furthermore, the ketimine is activated via protonation by chiral phosphoric acid $(S)-3 \mathrm{c}$ to form the $\mathrm{O} \cdots \mathrm{H} \cdots \mathrm{N}$ hydrogen bond (dashed blue lines in Fig. 2). More interestingly, in both of the transition states, an additional $\mathrm{C}-\mathrm{H} \cdots \mathrm{O}$ hydrogen bond forms between the $\alpha$-hydrogen atom of the methyl group attached to the ketimine and the phosphoryl oxygen of $(S)$-3c (2.25 $\AA$ in TSs-re and $2.14 \AA$ in TSr-si) (dashed
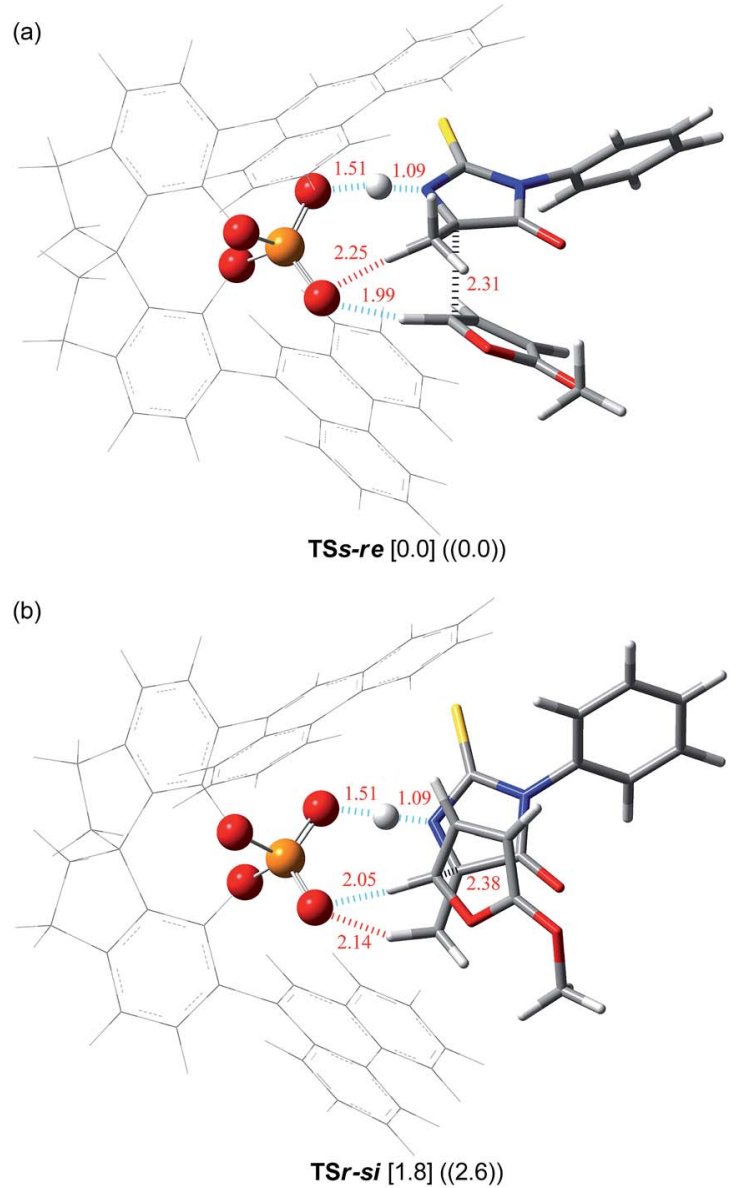

Fig. 2 Three-dimensional structures of transition states (a) TSs-re and (b) TSr-si. Relative energies (in $\mathrm{kcal} \mathrm{mol}^{-1}$ ) obtained by single-point energy calculations at the B3LYP/6-311+G** level and the M06-2X/6$311+G^{* *}$ level with the SCRF method based on PCM $(\in=2.2706$ for benzene) are shown in brackets and double parentheses, respectively. ${ }^{18}$ Bond lengths are shown in red $(\AA)$. red lines in Fig. 2). It can be considered that these two hydrogen bonds, $\mathrm{O} \cdots \mathrm{H} \cdots \mathrm{N}$ and $\mathrm{C}-\mathrm{H} \cdots \mathrm{O}$, fix the relative location between the ketimine and chiral phosphoric acid $(S)$-3c. It is obvious that the observed high enantioselectivity stems from the formation of the hydrogen bond network among the triad of components, resulting in a conformational fixation of the transition states. In the energetically favorable TSs-re, the ketimine and $\mathbf{6}$ are nearly parallel to the phenanthryl plane of the catalyst substituent to avoid steric congestion (Fig. 2a). In contrast, in the less-favorable TSr-si, both the ketimine and $\mathbf{6}$ are inserted perpendicularly between two phenanthryl planes (Fig. 2b), in which the methyl group of the ketimine locates close to the bottom phenanthryl substituent. This unfavorable interaction results in steric repulsion between the reactant and the catalyst (Fig. 2b), which would destabilize TSr-si.

The scope of the thiohydantoin derivatives were further investigated under the optimized reaction conditions (Table 2, entries 1-12). Initially, different alkyl substituents at the 5position were examined (entries 1-4). The reaction of isobutylsubstituted $\mathbf{4 b}$ proceeded smoothly to provide $\mathbf{7 b}$ in a high yield with a high ee (entry 1). ${ }^{19}$ In contrast, benzyl-substituted $\mathbf{4 c}$ required a longer reaction time for the full conversion of the substrate, and $7 \mathbf{c}$ was obtained in a moderate yield with a moderate enantioselectivity (entry 2). On the basis of the

Table 2 Substrate scope ${ }^{a}$

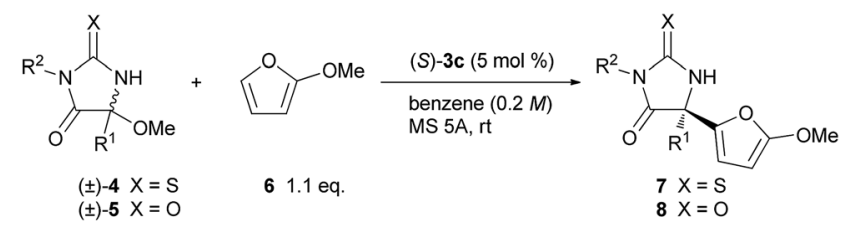

\begin{tabular}{llllllll}
\hline & $\mathbf{4}$ & & & & & \\
Entry & or $\mathbf{5}$ & $\mathrm{R}^{1}$ & $\mathrm{R}^{2}$ & or $\mathbf{8}$ & Time $(\mathrm{h})$ & Yield $^{b}(\%)$ & ee $^{c}(\%)$ \\
\hline 1 & $\mathbf{4 b}$ & $i \mathrm{Bu}$ & $\mathrm{Ph}$ & $\mathbf{7 b}$ & 4 & 98 & 86 \\
2 & $\mathbf{4 c}$ & $\mathrm{Bn}$ & $\mathrm{Ph}$ & $\mathbf{7 c}$ & 48 & 67 & 65 \\
3 & $\mathbf{4 d}$ & $i \mathrm{Pr}$ & $\mathrm{Ph}$ & $\mathbf{7 d}$ & 48 & $50^{d}$ & 85 \\
$4^{e}$ & $\mathbf{4 d}$ & $i \mathrm{Pr}$ & $\mathrm{Ph}$ & $\mathbf{7 d}$ & 24 & 89 & 78 \\
$5^{f}$ & $\mathbf{4 e}$ & $\mathrm{Me}$ & $4-\mathrm{MeOC}_{6} \mathrm{H}_{4}$ & $\mathbf{7 e}$ & 4 & 87 & 90 \\
6 & $\mathbf{4 f}$ & $i \mathrm{Bu}$ & $4-\mathrm{MeOC}_{6} \mathrm{H}_{4}$ & $\mathbf{7 f}$ & 4 & 98 & 90 \\
7 & $\mathbf{4 g}$ & $\mathrm{Me}$ & $4-\mathrm{BrC}_{6} \mathrm{H}_{4}$ & $\mathbf{7 g}$ & 4 & 97 & 90 \\
8 & $\mathbf{4 h}$ & $i \mathrm{Bu}$ & $4-\mathrm{BrC}_{6} \mathrm{H}_{4}$ & $\mathbf{7 h}$ & 4 & 99 & 88 \\
9 & $\mathbf{4 i}$ & $\mathrm{Me}$ & $3-\mathrm{BrC}_{6} \mathrm{H}_{4}$ & $\mathbf{7 i}$ & 4 & 99 & $67 / 94$ \\
10 & $\mathbf{4 j}$ & $\mathrm{Me}$ & $2-\mathrm{BrC}_{6} \mathrm{H}_{4}$ & $\mathbf{7 j}$ & 6 & $86(\mathrm{dr}=3: 2)$ & 90 \\
11 & $\mathbf{4 k}$ & $\mathrm{Me}$ & $\mathrm{Bn}$ & $\mathbf{7 k}$ & 4 & 98 & 90 \\
12 & $\mathbf{4 l}$ & $i \mathrm{Bu}$ & $\mathrm{Bn}$ & $\mathbf{7 l}$ & 4 & 99 & 93 \\
13 & $\mathbf{5 a}$ & $\mathrm{Me}$ & $\mathrm{Ph}$ & $\mathbf{8 a}$ & 24 & 86 & 92 \\
14 & $\mathbf{5 b}$ & $i \mathrm{Bu}$ & $\mathrm{Ph}$ & $\mathbf{8 b}$ & 24 & 98 & 89 \\
$15^{g}$ & $\mathbf{5 c}$ & $i \mathrm{Pr}$ & $\mathrm{Ph}$ & $\mathbf{8 c}$ & 48 & 51 & 93 \\
16 & $\mathbf{5 d}$ & $\mathrm{Me}$ & $\mathrm{Bn}$ & $\mathbf{8 d}$ & 36 & 95 & 97 \\
17 & $\mathbf{5 e}$ & $i \mathrm{Bu}$ & $\mathrm{Bn}$ & $\mathbf{8 e}$ & 36 & 97 &
\end{tabular}

${ }^{a}$ Reaction conditions: 4 or 5 ( $\left.0.10 \mathrm{mmol}\right), 6$ (0.11 mmol), $(S)-3 \mathrm{c}(5.0$ $\mu \mathrm{mol})$, MS 5A $(100 \mathrm{mg})$, benzene $(0.50 \mathrm{~mL}) .{ }^{b}$ Isolated yields. ${ }^{c}$ Enantiomeric excess of 7 and $\mathbf{8}$ were determined by chiral stationary phase HPLC analysis. ${ }^{d} 35 \%$ of $\mathbf{4 d}$ was recovered with $99 \%$ ee. ${ }^{e}$ Reaction was performed at $50{ }^{\circ} \mathrm{C} .{ }^{f} 1.0 \mathrm{~mL}$ of benzene was used. ${ }^{g} 10$ $\mu \mathrm{mol}$ of $(S)-3 \mathbf{c}(10 \mathrm{~mol} \%)$ was used. 
favorable transition state TSs-re as shown in Fig. 2a, the observed stereochemical outcome presumably arises from the steric repulsion between the phenanthryl substituent of catalyst 3c and the benzyl moiety introduced to substrate 4c. In this case, a substantial amount of enamide was formed via tautomerization of the imine generated in situ. The isopropylsubstituted $\mathbf{4 d}$ also could be applied to this reaction to yield $\mathbf{7 d}$ with high enantioselectivity; ${ }^{19}$ however, the reaction at room temperature did not achieve full conversion of the substrate, even after $24 \mathrm{~h}$, and a considerable amount of $\mathbf{4 d}$ was recovered (entry 3). The ee of the recovered 4d showed that it was enantiomerically pure, indicating that kinetic resolution of $4 \mathbf{d}$ occurred during the elimination of methanol to generate ketimine under the influence of the chiral phosphoric acid catalyst. $^{20}$ The higher temperature accelerated the reaction, however the ee was reduced (entry 4). Next, the effect of a substituent on the nitrogen at the 3-position was investigated. Substrates having an electron-donating group as well as an electron-withdrawing group at the para position of the phenyl group underwent a reaction to provide the corresponding products in high yields with high enantioselectivities (entries 5-8). meta-Bromophenyl-substituted $\mathbf{4 i}$ was also applicable to the reaction without any problem (entry 9). The reaction with ortho-bromosubstituted $\mathbf{4 j}$ provided a mixture of diastereomers due to the central chirality at the 5-position and the axial chirality around the $\mathrm{C}-\mathrm{N}$ bond between the ortho-bromophenyl group and the nitrogen at the 3-position (entry 10). The ee of the major diastereomer was moderate while that of the minor diastereomer was very high. The benzyl group was also a suitable substituent on the nitrogen, and the corresponding product was obtained in a high yield with a high ee (entries 11 and 12). The scope of this reaction was expanded by using the hydantoin derivatives 5 in addition to the thiohydantoin derivatives 4 (entries 13-17). Although the reaction of 5 required a longer reaction time compared with that of $\mathbf{4}$, the corresponding products 8 were obtained in high yields with high enantioselectivities, except for 8c which has an isopropyl group (entry 15).

Finally, derivatization of the product based on the 2methoxyfuryl moiety was performed (Scheme 2). The cleavage of the furan ring of $\mathbf{8 a}$ proceeded smoothly under Achmatowicz type reaction conditions, ${ }^{21}$ and subsequent chemoselective reduction of the keto moiety under Luche conditions resulted in

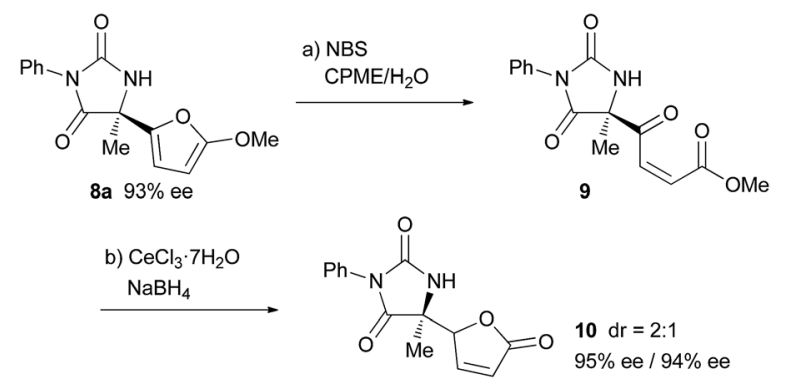

Scheme 2 Derivatization of 8a. Reagents and conditions: (a) NBS (1.1 eq.), $\mathrm{CPME} / \mathrm{H}_{2} \mathrm{O}, 0{ }^{\circ} \mathrm{C}, 30 \mathrm{~min}$. (b) $\mathrm{CeCl}_{3} \cdot 7 \mathrm{H}_{2} \mathrm{O}$ (1.5 eq.), $\mathrm{NaBH}_{4}$ (1.0 eq.), $-78{ }^{\circ} \mathrm{C}$ to $r$, $3 \mathrm{~h}, 78 \%$ (over 2 steps), $d r=2: 1,95 \%$ ee/ $94 \%$ ee. the formation of butenolide $\mathbf{1 0}$ in a good yield over two steps. In the course of the derivatization, the loss of enantiomeric purity did not occur. ${ }^{22}$

\section{Conclusions}

In conclusion, we have successfully developed an enantioselective Friedel-Crafts reaction of 2-methoxyfuran with aliphatic ketimines generated in situ from thiohydantoin- and hydantoinderived hemiaminal methyl ether under the influence of a chiral phosphoric acid catalyst. This reaction is a rare example of the Friedel-Crafts reaction involving ketimines possessing alkyl substituents, such as isobutyl and isopropyl groups, and is also an attractive method for the synthesis of (thio)hydantoin derivatives which have a quaternary stereogenic center at the 5position. In addition, theoretical studies were conducted to clarify the origin of the stereochemical outcome as well as the major factors contributing to the efficient enantioselection, which would contribute to developing new enantioselective reactions catalyzed by chiral phosphoric acid.

\section{Acknowledgements}

This research was partially supported by a Grant-in-Aid for Scientific Research on Innovative Areas "Advanced Molecular Transformations by Organocatalysts” from MEXT (Japan) and a Grant-in-Aid for Scientific Research from the JSPS.

\section{Notes and references}

1 (a) V. Terrasson, R. M. de Figueiredo and J. M. Campagne, Eur. J. Org. Chem., 2010, 2635; (b) S.-L. You, Q. Cai and M. Zeng, Chem. Soc. Rev., 2009, 38, 2190; (c) M. Zeng and S.-L. You, Synlett, 2010, 1289; (d) M. Bandini and A. Eichholzer, Angew. Chem., Int. Ed., 2009, 48, 9608; (e) M. Bandini, A. Melloni and A. Umani-Ronchi, Angew. Chem., Int. Ed., 2004, 43, 550.

2 (a) M. Abid, L. Teixeira and B. Török, Org. Lett., 2008, 10, 933; (b) M. Rueping, S. Raja and A. Núñez, Adv. Synth. Catal., 2011, 353, 563; (c) R. Husmann, E. Sugiono, S. Mersmann, G. Raabe, M. Rueping and C. Bolm, Org. Lett., 2011, 13, 1044; (d) Y. Qian, C. Jing, C. Zhai and W.-h. Hu, Adv. Synth. Catal., 2012, 354, 301; (e) J. Feng, W. Yan, D. Wang, P. Li, Q. Sun and R. Wang, Chem. Commun., 2012, 48, 8003; $(f)$ E. Aranzamendi, N. Sotomayor and E. Lete, J. Org. Chem., 2012, 77, 2986; (g) K.-F. Zhang, J. Nie, R. Guo, Y. Zheng and J.-A. Ma, Adv. Synth. Catal., 2013, 355, 3497; (h) T. Kano, R. Takechi, R. Kobayashi and K. Maruoka, Org. Biomol. Chem., 2014, 12, 724.

3 (a) Y.-X. Jia, J. Zhong, S.-F. Zhu, C.-M. Zhang and Q.-L. Zhou, Angew. Chem., Int. Ed., 2007, 46, 5565; (b) M. Rueping and B. J. Nachtsheim, Synlett, 2010, 119; (c) Q. Yin and S.-L. You, Chem. Sci., 2011, 2, 1344; (d) X. Yu, Y. Wang, G. Wu, H. Song, Z. Zhou and C. Tang, Eur. J. Org. Chem., 2011, 3060; (e) M. Righi, F. Bartoccini, S. Lucarini and G. Piersanti, Tetrahedron, 2011, 67, 7923. 
4 For reviews on chiral Brønsted acid catalysis, see: (a) T. Akiyama, Chem. Rev., 2007, 107, 5744; (b) T. Akiyama, J. Itoh and K. Fuchibe, Adv. Synth. Catal., 2006, 348, 999; (c) M. S. Taylor and E. N. Jacobsen, Angew. Chem., Int. Ed., 2006, 45, 1520; (d) A. G. Doyle and E. N. Jacobsen, Chem. Rev., 2007, 107, 5713; (e) H. Yamamoto and N. Payette, in Hydrogen Bonding in Organic Synthesis, ed. P. M. Pihko, Wiley-VCH, Weinheim, 2009, p. 73; (f) D. Kampen, C. M. Reisinger and B. List, Top. Curr. Chem., 2010, 291, 395; (g) M. Terada, Synthesis, 2010, 1929; (h) D. Parmar, E. Sugiono, S. Raja and M. Rueping, Chem. Rev., 2014, 114, 9047; For seminal studies, see: (i) T. Akiyama, J. Itoh, K. Yokota and K. Fuchibe, Angew. Chem., Int. Ed., 2004, 43, 1566; (j) D. Uraguchi and M. Terada, J. Am. Chem. Soc., 2004, 126, 5356.

5 L. Simón and J. M. Goodman, J. Org. Chem., 2010, 75, 589.

6 (a) L. Simón and J. M. Goodman, J. Am. Chem. Soc., 2008, 130, 8741; (b) T. Marcelli, P. Hammar and F. Himo, Chem.-Eur. J., 2008, 14, 8562; (c) L. Simón and J. M. Goodman, J. Org. Chem., 2010, 75, 589; (d) Y. Shibata and M. Yamanaka, J. Org. Chem., 2013, 78, 3731; (e) K. Saito, Y. Shibata, M. Yamanaka and T. Akiyama, J. Am. Chem. Soc., 2013, 135, 11740; ( $f$ ) K. Saito, K. Horiguchi, Y. Shibata, M. Yamanaka and T. Akiyama, Chem.-Eur. J., 2014, 20, 7616.

7 (a) M. Terada, K. Machioka and K. Sorimachi, Angew. Chem., Int. Ed., 2009, 48, 2553; (b) M. Terada and Y. Toda, J. Am. Chem. Soc., 2009, 131, 6354; (c) M. Terada, T. Komuro, Y. Toda and T. Korenaga, J. Am. Chem. Soc., 2014, 136, 7044. 8 Selected examples on thiohydantoin derivatives, see: $(a)$ T. Mendgen, C. Steuer and C. D. Klein, J. Med. Chem., 2012, 55, 743; (b) Y. Liu, J. Wu, P.-Y. Ho, L.-C. Chen, C.-T. Chen, Y.-C. Liang, C.-K. Cheng and W.-S. Lee, Cancer Lett., 2008, 271, 294; (c) M. E. Jung, S. Ouk, D. Yoo, C. L. Sawyers, C. Chen, C. Tran and J. Wongvipat, J. Med. Chem., 2010, 53, 2779; (d) A. Takahashi, H. Matsuoka, Y. Ozawa and Y. Uda, J. Agric. Food Chem., 1998, 46, 5037; (e) A. A. El-Barbary, A. I. Khodair, E. B. Pedersen and C. Nielsen, J. Med. Chem., 1994, 37, 73; (f) J. Marton, J. Enisz, S. Hosztafi and T. Tímár, J. Agric. Food Chem., 1993, 41, 148; (g) J. E. Tompkins, J. Med. Chem., 1986, 29, 855; (h) J. V. Marx, D. A. Richert and W. W. Westerfeld, J. Med. Chem., 1970, 13, 1179.

9 For reviews on hydantoin derivatives, see: (a) E. Ware, Chem. Rev., 1950, 46, 403; (b) C. A. López and G. G. Trigo, Adv. Heterocycl. Chem., 1985, 38, 177; (c) M. Meusel and M. Gutschow, Org. Prep. Proced. Int., 2004, 36, 391.

10 For selected recent synthetic studies on thiohydantoin derivatives, see: (a) O. A. Attanasi, L. de Crescentini, P. Filippone, G. Giorgi, S. Nicolini, F. R. Perrulli and S. Santeusanio, Tetrahedron, 2014, 70, 7336; (b) V. Mehra, P. Singh, N. Manhas and V. Kumar, Synlett, 2014, 25, 1124; (c) S. Gosling, C. E. Amri and A. Tatibouët, Synthesis, 2014, 46, 1079; (d) V. Ceban, K. Hands, M. Meazza, M. E. Light and R. Rios, Tetrahedron Lett., 2013, 54, 7183; (e) F. Medda and C. Hulme, Tetrahedron Lett., 2012, 53, 5593; (f) V. Kumar, H. Rana, R. Sankolli and M. P. Kaushik, Tetrahedron Lett., 2012, 53, 2377; $(g)$ G. Baccolini, C. Boga,
C. Delpivo and G. Micheletti, Tetrahedron Lett., 2011, 52, 1713; (h) F. Xiang, S. Zhang, C. Lu, Z. Chen and G. Yang, Synth. Commun., 2008, 38, 953; (i) M. Carboni, J.-M. Gomis, O. Loreau and F. Taran, Synthesis, 2008, 417; (j) G. S. M. Sundaram, C. Venkatesh, H. Ila and H. Junjappa, Synlett, 2007, 251; (k) S. Porwal, R. Kumar, P. R. Maulik and P. M. S. Chauhan, Tetrahedron Lett., 2006, 47, 5863; $(l)$ S. Reyes and K. Burgess, J. Org. Chem., 2006, 71, 2507.

11 For selected recent synthetic studies on hydantoin derivatives, see: (a) H. Liu, Z. Yang and Z. Pan, Org. Lett., 2014, 16, 5902; (b) M. C. Hillier, H.-H. Gong, D. S. Clyne and M. J. Babcock, Tetrahedron, 2014, 70, 9413; (c) H. Rmedi and A. Baklouti, Tetrahedron Lett., 2014, 55, 3585; (d) P. Ventosa-Andrés, J. A. González-Vera, M. T. García-López and R. Herranz, Tetrahedron, 2014, 70, 3407; (e) G. Chaubet, G. Cazals, A. Lebrun, J. Martinez and I. Parrot, Synlett, 2014, 25, 574; (f) C. Menor-Salván and M. R. Marín-Yaseli, Chem.-Eur. J., 2013, 19, 6488; $(g)$ M. C. Bellucci, M. Frigerio, T. Marcelli and A. Volonterio, Synlett, 2013, 24, 727; (h) V. Mehra and V. Kumar, Tetrahedron Lett., 2013, 54, 6041.

12 D. Uraguchi, K. Sorimachi and M. Terada, J. Am. Chem. Soc., 2004, 126, 11804.

13 A preliminary investigation of the reaction conditions, including the screening of solvents, was conducted. See the $\mathrm{ESI} \dagger$ for details.

14 CCDC no. $1405286[(S)-7 a] \dagger$ contains the supplementary crystallographic data for this paper.

15 All calculations were performed with the Gaussian 09 package. M. J. Frisch, et al., Gaussian 09, Revision C.01, Gaussian, Inc., Wallingford, CT, 2010. See the ESI $\uparrow$ for the full citation.

16 (a) A. D. Becke, Phys. Rev. A, 1988, 38, 3098; (b) C. Lee, W. Yang and R. G. Parr, Phys. Rev. B: Condens. Matter Mater. Phys., 1988, 37, 785.

17 The orientation of the phenanthryl group was thoroughly optimized in the transition states TSs-re and TSr-si. See the $\mathrm{ESI} \dagger$ for details.

18 (a) B. Mennucci and J. Tomasi, J. Chem. Phys., 1997, 106, 5151; (b) Y. Zhao and D. Truhlar, Theor. Chem. Acc., 2008, 120, 215.

19 The stereochemical outcome of the reactions of the other ketimines having isobutyl and isopropyl substituents can be also rationalized by similar transition states shown in Fig. 2. See the $\mathrm{ESI}_{\dagger} \dagger$ for details of three-dimensional structures and energies.

20 In order to experimentally validate the proposed reaction mechanism involving the formation of imine from hemiaminal ethers, we carried out a control experiment. Thus, the possibility of the other reaction mechanism such as the $\mathrm{S}_{\mathrm{N}}$ 2-type mechanism including dynamic kinetic resolution was examined. Treatment of enantiomericallypure 4d with a catalytic amount of achiral diphenyl phosphate, $(\mathrm{PhO})_{2} \mathrm{P}(=\mathrm{O}) \mathrm{OH}$, provided the corresponding adduct $7 \mathbf{d}$ in a 55\% yield in a completely racemic form. This result clearly reveals that the involvement of the $\mathrm{S}_{\mathrm{N}} 2$ type mechanism is ruled out and indirectly supports our proposed mechanism. For the kinetic resolution through the $\mathrm{S}_{\mathrm{N}} 2$ reaction catalyzed by chiral phosphoric acid, also 
see: I. Čorić, J. H. Kim, T. Vlaar, M. Patil, W. Thiel and B. List, Angew. Chem., Int. Ed., 2013, 52, 3490.

21 For a review on the aza-Achmatowicz reaction, see: F. van der Pijl, F. L. van Delft and F. P. J. T. Rutjes, Eur. J. Org. Chem., 2015, 4811.

22 The high acidity of the proton at the $\gamma$ position of the butenolide moiety of $\mathbf{1 0}$ allowed the epimerization at that position to proceed easily, even during column purification, and a 2:1 diastereomixture was obtained from each attempt for the transformation of $\mathbf{9}$ to $\mathbf{1 0}$ under different reaction conditions. Thus the $2: 1$ ratio is assumed to be thermodynamically determined. 